\title{
Experimental and Numerical Analysis of Post-Critical States and Damage of Thin-Walled Channel Section Columns Made of Carbon/Epoxy Composite
}

\author{
Hubert Debski ${ }^{*}$, Jarosław Bienias² \\ 1 Department of Machine Design and Mechatronics, Faculty of Mechanical Engineering, Lublin University of \\ Technology, Nadbystrzycka 36, 20-618 Lublin, Poland \\ 2 Department of Materials Engineering, Faculty of Mechanical Engineering, Lublin University of Technology, \\ Nadbystrzycka 36, 20-618 Lublin, Poland \\ * Corresponding author's e-mail: h.debski@pollub.pl
}

\begin{abstract}
The paper presents results of a numerical and experimental analysis of post-critical state of a thin-walled channel-section simply supported beam under axial compression. The beam was made of carbon-epoxy symmetrical composite prepared with a pre-preg technology using 8 layers of unidirectional band. The material used was a composite of epoxy matrix reinforced with carbon fiber (system HexPly M12, Hexcel). The M12 system is used above all in aircraft structures. It exhibits high fatigue durability and good maintenance properties at relatively low specific gravity. The research was lead as the FEM numerical analyses and experimental tests in post-buckling and limit states, as well. Experimental studies were conducted to confirm results obtained from numerical calculations, which was performed using the ABAQUS ${ }^{\circledR}$ software.
\end{abstract}

Keywords: composites, computer modeling, failure, fibers, structure.

\section{INTRODUCTION}

Thin-walled structures are part of the category of load-carrying structures that have to meet strict strength and rigidity requirements and, at the same time, have the lowest weight possible [1]. In particular, this concerns the latest solutions applied in the aerospace and automotive industries, where structures of this type are most widely applied. It was possible to considerably improve their strength properties and to reduce weight due to the use of modern structural materials such as fibrous polymer-matrix composites, also known as laminates, reinforced with glass or carbon fibers. Given modern manufacturing technologies, these materials can be applied in thin-walled structures as loadcarrying elements, hence replacing traditionally used metals. So is the case with thin-walled profiles of complex cross section shapes which are used in modern aircraft structures as coating stiffeners.
Nowadays carbon fibers are the leading type of fibers used as polymer composite reinforcement. These fibers are characterized by a very good combination of physical and chemical properties, including high strength at low density, low coefficient of thermal expansion, and conductive properties. Despite the fact that the fibers exhibit brittleness (elongation below $2 \%$ ) and low impact strength [2], they are, however, characterized by very high fatigue strength when used in composite material structures [3].

One of the most advanced processes for manufacturing composite materials is the autoclave method [4-7]. Composite elements manufactured by the autoclave method meet all the criteria for primary structures [6]. Composite materials manufactured by the autoclave method exhibit favorable characteristics that cannot be obtained with other manufacturing processes. These characteristics include, among others, high mechanical properties, 
high quality of both composites and surfaces, repeatability and complete control of the manufacturing process (the process is automated), complete control of the detail in the hardening process (temperature, pressure) and minimal porosity $(<1 \%)$.

The study presents results of the research on post-critical and limit states in thin-walled channel section columns subjected to axial compression. The research involved measuring the parameters of the structure's operation for entire load range until failure. The tests consisted in the axial compression of manufactured channel section columns articulately jointed on both profile ends. To determine a failure moment of the composite material, the acoustic emission method (AEM) was applied $[8,9]$. Also, a high speed camera was used to visualize advanced post-critical states and damage of the composite material structure. A detailed analysis of the damage process of the composite material structure was performed using the NDT methods, optical macroscopy and X-ray microtomography. In effect, it was possible to accurately describe damage areas of the structure and to identify basic failure mechanisms of the composite. In order to analyze the problem of non-linear stability and load capacity of the tested composite profiles, numerical calculations were performed using the finite element method. The experimental results were then used as a basis for developing adequate FEM models simulating real conditions of the experiment.

\section{RESEARCH METHODOLOGY}

The composites were manufactured by the autoclave method at the Department of Materials Engineering at the Lublin University of Technology. The manufacturing process involved preparing a mold to map the dimensions and shape of the profiles being manufactured (Fig. 1), forming a composite panel, preparing a vacuum package and, finally, autoclave hardening.

Thin-walled channel section columns were made of HexPly carbon/epoxy prepreg unidirectional tape from Hexcel. The matrix of the composite was made of epoxy resin (density: $1.24 \mathrm{~g} / \mathrm{cm}^{3}$; $\mathrm{Tg}: 128{ }^{\circ} \mathrm{C} ; \mathrm{R}_{\mathrm{m}}$ : $64 \mathrm{MPa}$; v: 0.4; E: $5.1 \mathrm{GPa}$ ), while the reinforcement was made of AS7J12K carbon fibers (density: $2.5 \mathrm{~g} / \mathrm{cm}^{3}$; $\mathrm{R}_{\mathrm{m}}$ : $4830 \mathrm{MPa}$; v: 0.269; E: $241 \mathrm{GPa})$. The rated volume fraction of the reinforcement in the composite amounted to about $60 \%$. The structure of the laminate consisted of 8 layers, each layer being $0.131 \mathrm{~mm}$ thick in a symmetrical layer arrangement relative to the central plane of the package in a configuration of $[90 /+45 /-45 / 0]_{\mathrm{s}}$ and a column length of $\mathrm{L}=300 \mathrm{~mm}$. Figure 2 shows a schematic drawing of the channel section column, where the dimensions are given in [mm].

The prepared vacuum package was first connected to a vacuum pump that produced a negative pressure of about $0.08 \mathrm{MPa}$ and then subjected to polymerization in the autoclave. The hardening process in the autoclave was caused, first, by a rapid increase in temperature under controlled pressure conditions, then by isothermal soaking in the time required for polymerization to occur, and, finally, by cooling. For the carbon/epoxy composite, the excess pressure in the autoclave was set to $0.4 \mathrm{MPa}$, the negative pressure in the vacuum bag was set to $0.08 \mathrm{MPa}$, while the temperature of soaking was set to 135 ${ }^{\circ} \mathrm{C}$ for a duration of 2 hours. Additionally, the package was subjected to heating and cooling at precise velocity control set to $2{ }^{\circ} \mathrm{C} / \mathrm{min}$. This is significant, as too rapid heating could lead to an a)

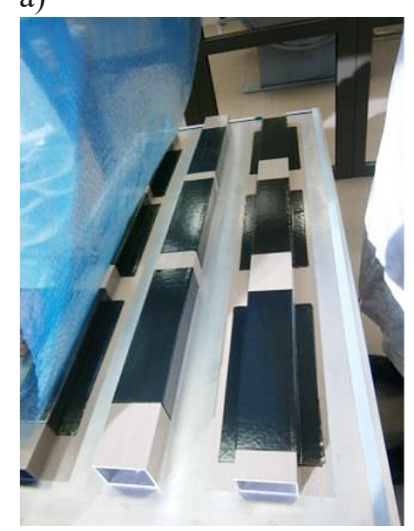

b)

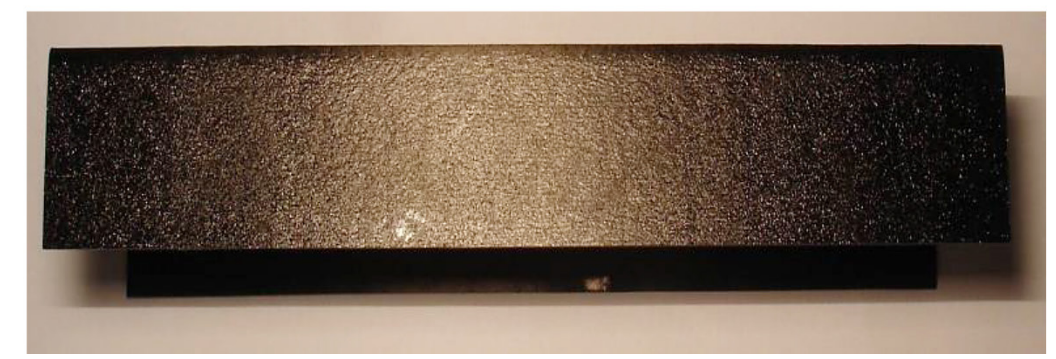

Fig. 1. Manufacturing of composite profiles: a) prepreg profiles forming, b) C-type profile 


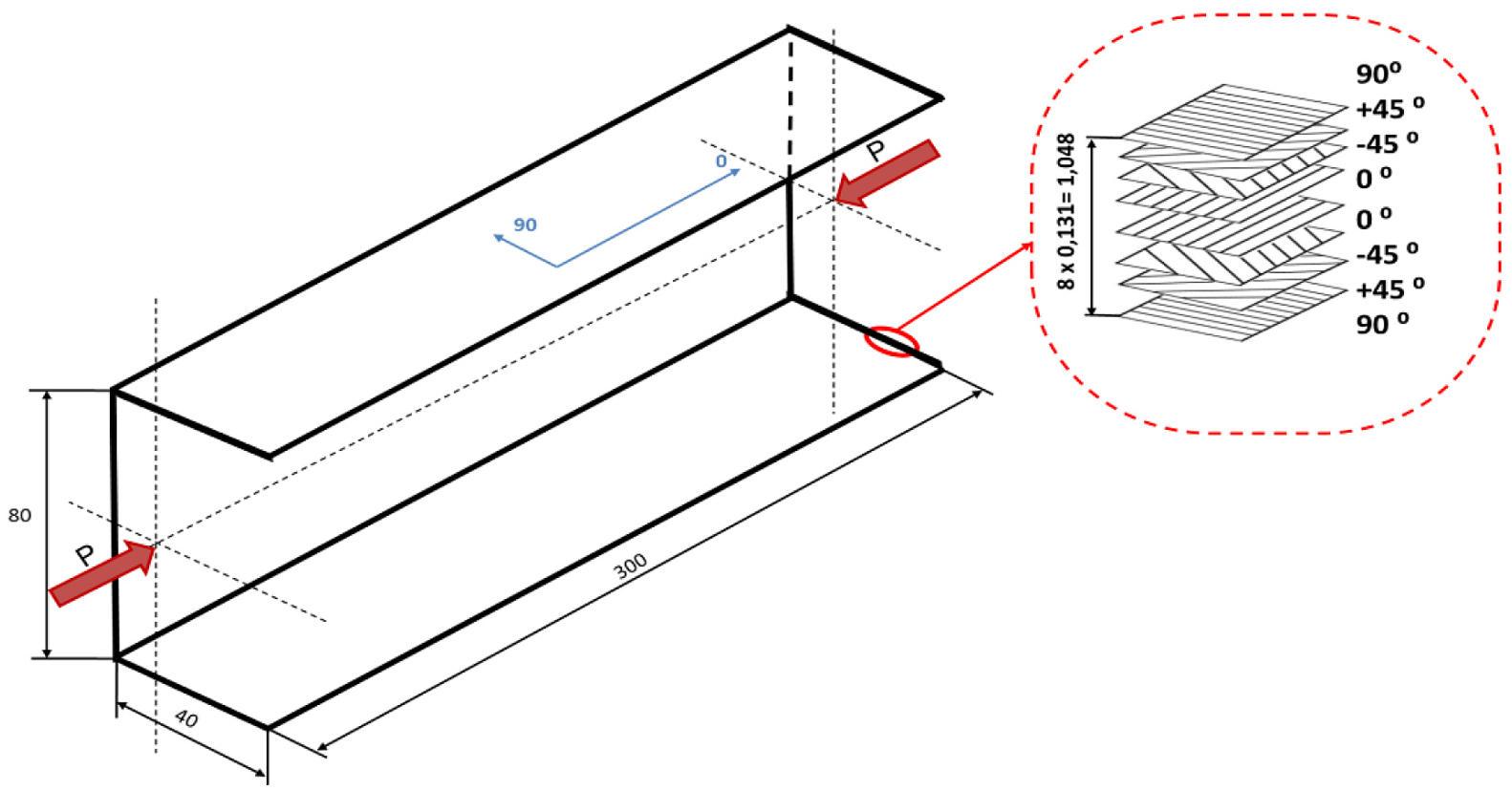

Fig. 2. Schematic drawing of the thin-walled column and layer arrangement in the composite

excessive increase in thermal stresses in the material, whereas too rapid cooling could limit the relaxation of primary and thermal stresses, which is the most frequent cause of waviness that occurs during the forming of elements [10].

In order to identify the character of damage in the tested composite columns, ultrasonic NDT (Non-Destructive Testing) methods were employed, specifically the echo method based on the phased array technique [11, 12]. The tests were conducted with the OmniScan MXU-M ultrasonic flaw detector equipped with the Olympus 5L64 A12 measuring head and the wedge-type SA12-OL delay. The following test parameters were applied: a frequency of $5 \mathrm{MHz}$, a wave propagation velocity of $3100 \mathrm{~m} / \mathrm{s}$ and an amplification level of 6-8 dB.

Moreover, for the purpose of the laminates' failure analysis microstructural tests were performed: optical microscopy (Nikon MA200) and X-ray microtomography (SkyScan 1174). The applied methods for failure identification in the internal areas of the material will allow a better understanding of phenomena that occur at a moment of failure.
Strength properties of the manufactured composites were experimentally determined in compliance with the ISO standard specification for this type of materials. The experiments involved determining basic mechanical properties of the material with regard to fiber arrangement, i.e. Young's modulus $\mathrm{E}_{1}$ and $\mathrm{E}_{2}$, Poisson's ratio as well as Kirchhoff's modulus. In addition, limit parameters of the materials were determined in destructive tensile, compression and shearing tests. The values determined are listed in Table 1 .

\section{EXPERIMENTAL TESTS AND NUMERICAL ANALYSIS}

The experimental tests for the autoclave-produced thin-walled channel section columns were performed using the ZWICK 100 testing machine. The experiments were conducted in room temperature at a constant cross-beam velocity of $2 \mathrm{~mm} /$ $\mathrm{min}$. The experiments involved examining the operation of the structure at advanced post-critical states and at failure moment. To this aim, the structure's deformations were measured in a region with

Table 1. Mechanical properties of the tested carbon/epoxy composite

\begin{tabular}{|c|c|c|c|c|c|c|c|c|}
\hline \multicolumn{2}{|c|}{$\begin{array}{c}\text { Tensile strength } \\
\mathrm{F}_{\mathrm{TU}}[\mathrm{MPa}]\end{array}$} & \multicolumn{2}{c|}{$\begin{array}{c}\text { Tensile modulus } \\
\mathrm{E}_{\mathrm{T}}[\mathrm{GPa}]\end{array}$} & $\begin{array}{c}\text { Poisson's } \\
\text { ratio } \mathrm{v}_{12}\end{array}$ & $\begin{array}{c}\text { Shear } \\
\text { strength } \\
\mathrm{F}_{\mathrm{SU}}[\mathrm{MPa}]\end{array}$ & $\begin{array}{c}\text { Shear } \\
\text { modulus } \\
\mathrm{G}[\mathrm{GPa}]\end{array}$ & $\begin{array}{c}\text { Compression strength } \\
\mathrm{F}_{\mathrm{CU}}[\mathrm{MPa}]\end{array}$ \\
\hline $0^{\circ}$ & $90^{\circ}$ & $0^{\circ}$ & $90^{\circ}$ & & $\pm 45^{\circ}$ & $\pm 45^{\circ}$ & $0^{\circ}$ & $90^{\circ}$ \\
\hline 1867.2 & 25.97 & 130.71 & 6.36 & 0.32 & 100.15 & 4.18 & 1531 & 214 \\
\hline
\end{tabular}




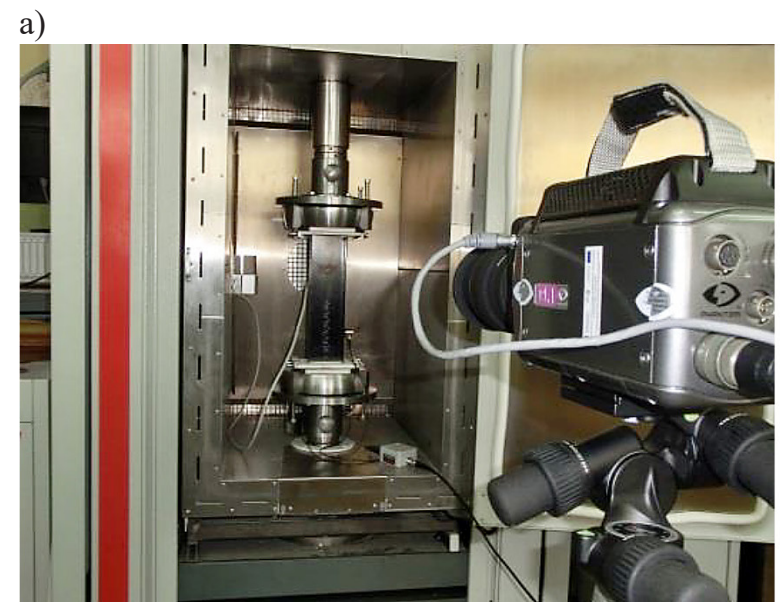

b)

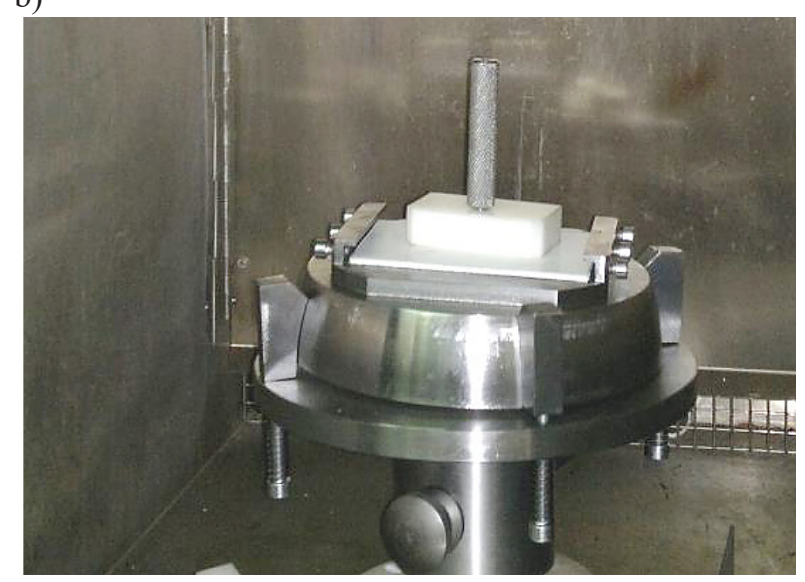

Fig. 3. Experimental tests: a) test stand, b) articulated grip

the highest deflections of the web using resistance extensometry and profile wall deflection by a laser sensor, depending on load. The composite columns were articulately jointed on both ends by means of specially designed grips with a spherical articulate joint to ensure alignment of the samples in the pins of the testing machine. Any inaccuracies of the column end sections were compensated by the application of special inserts made of soft plastic that allowed the positioning of the edges of the column end sections in the grips, eliminating, at the same time, undesired boundary effects that could occur during the experiment (Fig. 3).

The structure deformation at advanced postcritical and limit states was examined using a rapid speed camera. Failure initiaton moment of the composite structure was estaimated by the Acoustic Emission Method (AEM), which allowed to register acoustic effects occurring in the composite material structure during the loading process. The experiments were performed on three samples of the channel section columns for entire load range until total loss of load-carrying capacity of the structure.

Along with the experimental tests, a numerical analysis by the finite element method (FEM) was performed. The numerical analysis was performed for the models of columns with initiated geometrical imprefection corresponding to the lowest buckling mode, whose amplitude was 0.1 of the column wall thickness [13-17]. The numerical analysis was performed for a non-linear geometrical problem, where the Newton-Raphson method was applied [18]. The discretization process assumed a plate_model of the structure, based on S8R elements, i.e. elements with reduced integration and quadratic shape function. Each node of the element had six degrees of freedom. The applied element type was multi-layered and it allowed for defining the composite material structure via idependent defining of individual layers at a given thickness of the element. The analysis was performed using the elastic orthrotropic model in a two-dimensional stress state, where the principal orthrotropic directions were the same as the directions of fibre orientation in the laminate's layer [19]. A general view of the numerical model of the channel section columns is presented in Figure 4.

Real conditions of the experiment were simulated by means of calculations which took into account the effect of boundary conditions on failure load. The test results demonstrated that the most adequate way of jointing the column's ends is to employ the model which allows for rigid rotation of the upper section of the column, preventing, at the same time, such rotation for the bottom section (Fig. 4). As for the model allowing a simultaneous rotation of both ends of the column and the one allowing for even approaching of the column ends during load, the results obtained considerably differ from those obtained experimentally, where the possibility of rotation of the movable articulated grip was observed at failure moment. The aim of including the three variants of boundary conditions in the numerical analysis was to point to the fact that the FEM model should describe as closely as possible real boundary conditions of the examined columns. The model load was performed via loading the edges of the upper end section of the column, which ensured its uniform compression in an axial direction. The applied numerical tool was ABAQUS ${ }^{\circledR}$, a software suite for finite element analysis. 


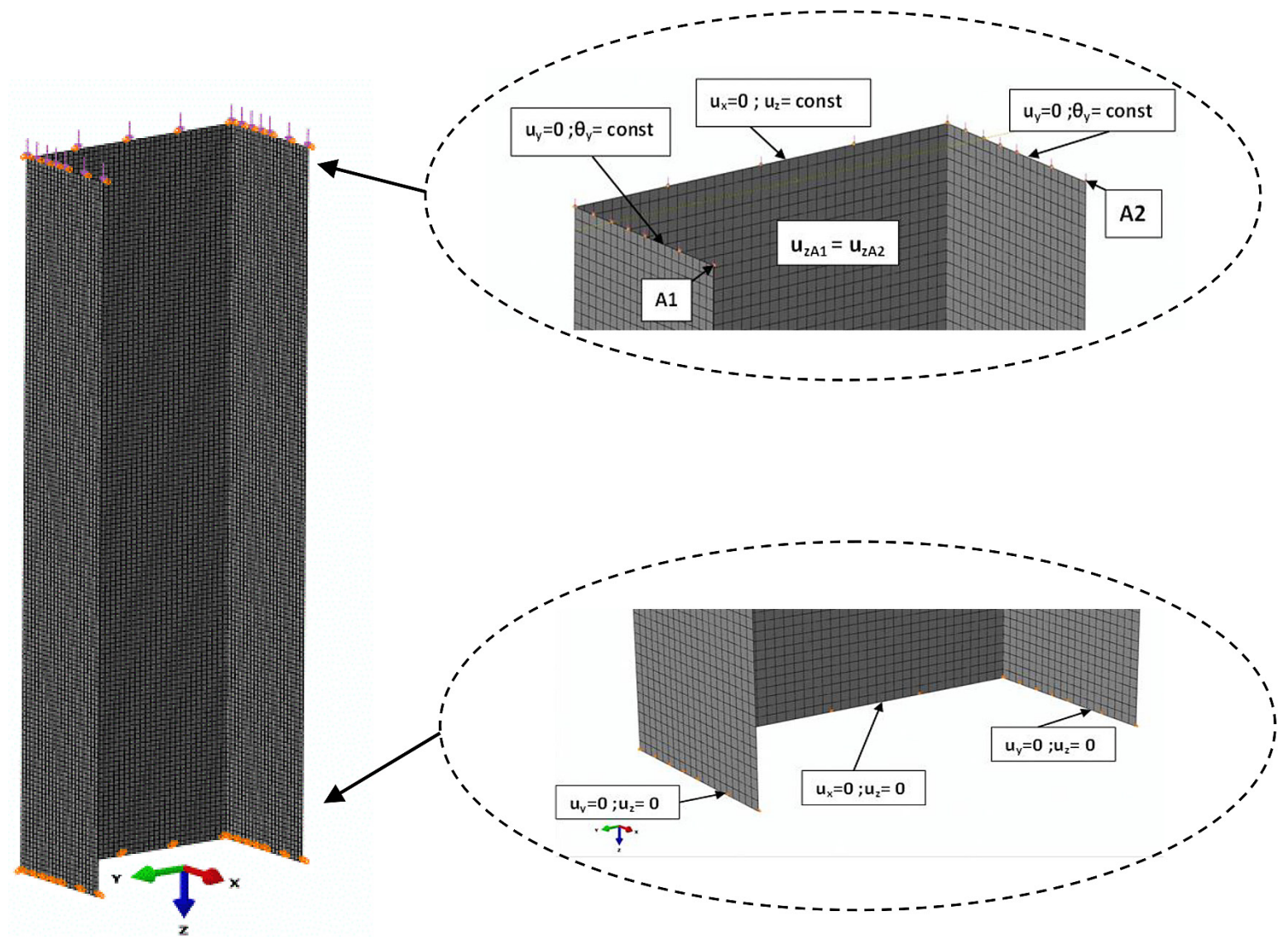

Fig. 4. Discrete model of the channel section column

\section{STRUCTURAL DAMAGE ANALYSIS: A COMPARISON OF RESULTS}

The tests allowed to examine forms of deformation and to measure the required test parameters until a moment of failure. During loading, the forms of structure stability loss were more and more advanced and they corresponded to the lowest buckling mode. The loss of load-carrying capacity of the examined channel section columns occurred once the limit load was reached, without any previous signs of local material damage. The damage process was rapid, from short material cracking to a complete loss of load-carrying capacity of the column. Figure 5 shows the recorded image of the structure at advanced post-critical state and moment of failure.

Based on the results obtained with the testing machine, post-critical equilibrium paths $P-\varepsilon$ (load-strain) were determined, which were then compared with the results obtained by the acoustic emission method. The results with regard to structural load made it possible to compare the postcritical equilibrium path and the recorded acoustic emission signals, including real-time energy, amplitude and the number of counts (Fig. 6).
Figure 6a shows strain curves for the channel section profile web in the place of maximum deflections, where resistance extensometers were fixed on both ends. An analysis of the postcritical equilibrium path $P-\varepsilon$ demonstrates that the path has a local break-point denoted by A, accompanied by a temporary drop in column load. As can be seen from the curves representing the acoustic emission results (Figs. 6b, c, d), this point is also the place where an increase in acoustic emission signal was observed at the same time, which can point to the occurrence of certain phenomena inside the microstructure of the composite material. The signals were assumed to be the first signs of failure in certain areas of the first layer of the composite material. The value of load corresponding to the observed post-critical equilibrium path breakpoint was set to be the value of failure initiation load $P_{f(i n i)-E X P}$ for the first composite layer. As seen from the charts, the load value does not put an end to the column's load-carrying capacity, which is proved by the subsequent increase in the structure's load until the limit load value $P_{f-E X P}$, when the structure fails. 

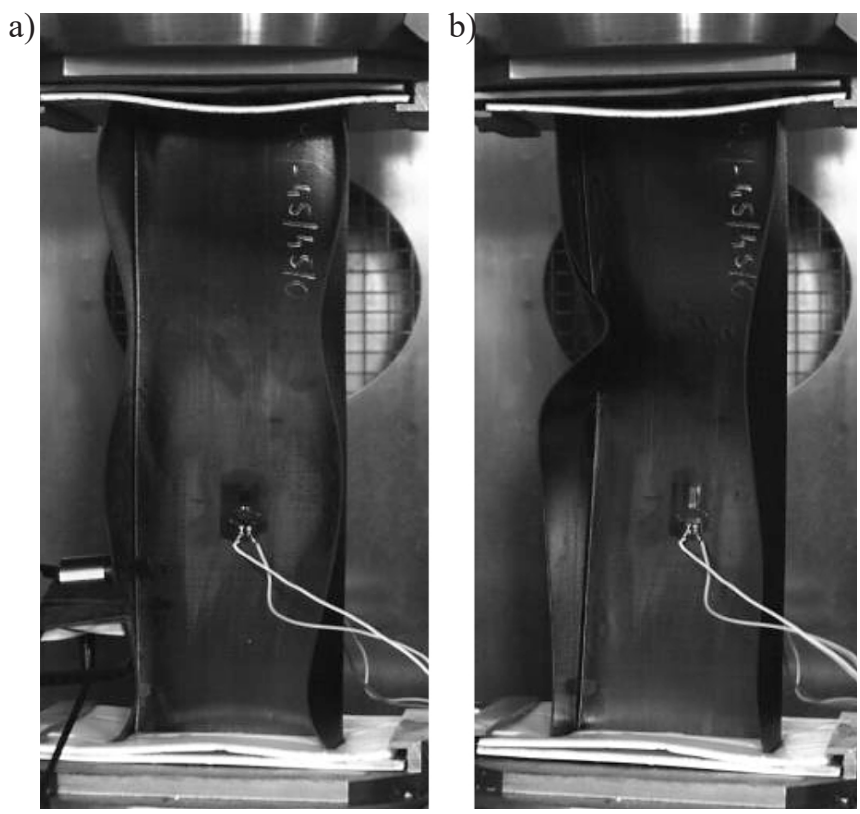

Fig. 5. Experimental tests of channel section columns: a) post-critical state, b) failure moment

a)

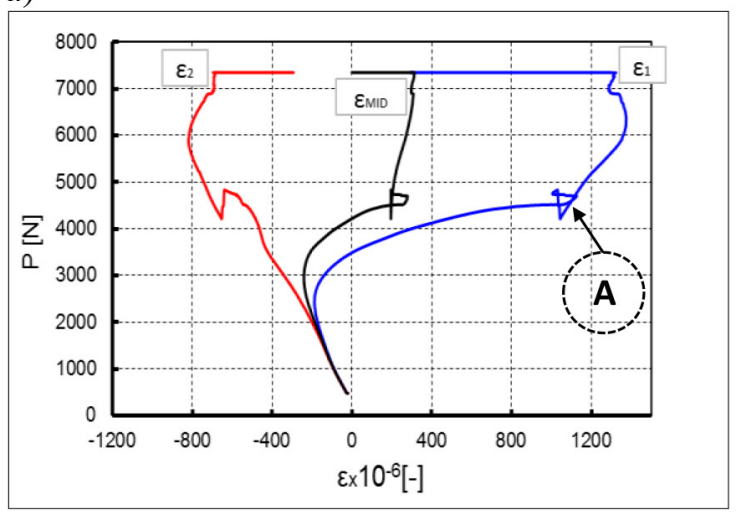

c)

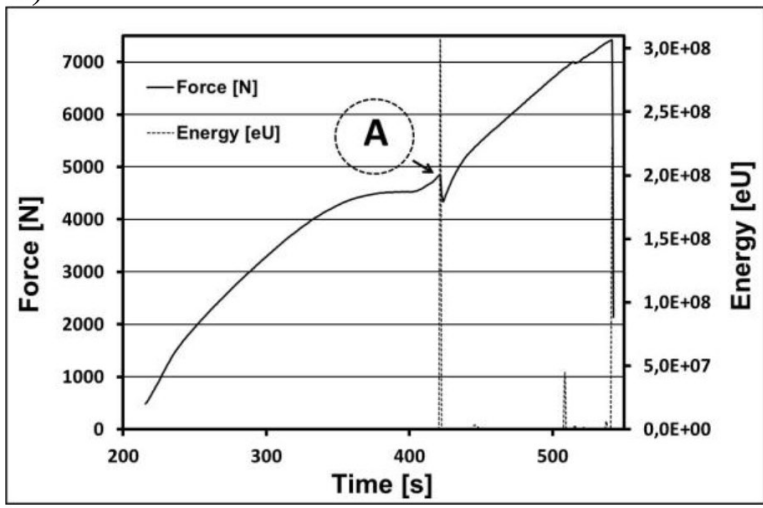

b)

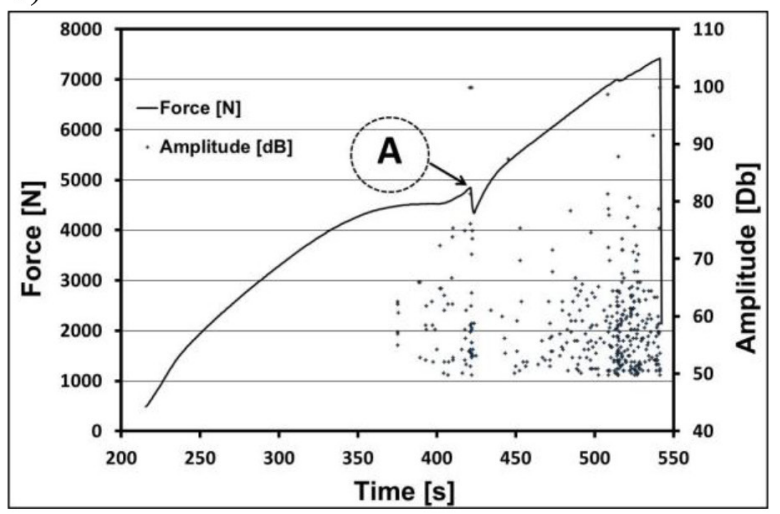

d)

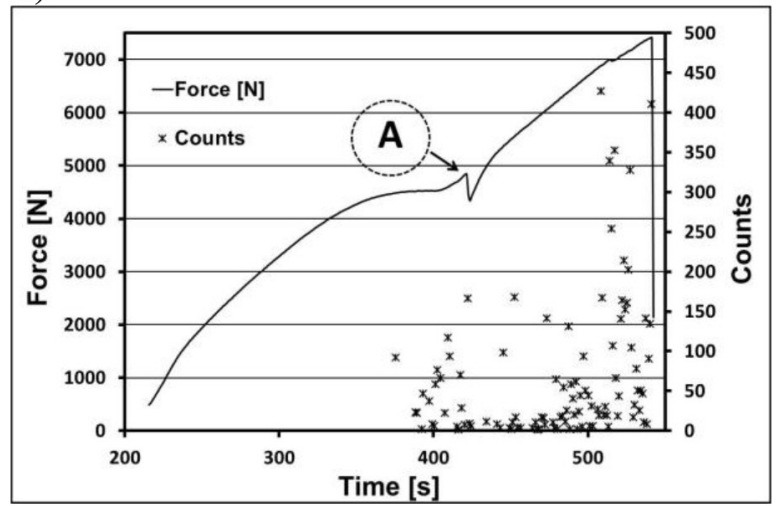

Fig. 6. Experimental results for Sample 1: a) testing machine $\mathrm{P}-\varepsilon, \mathrm{b}$ ) acoustic emission signal amplitude, c) acoustic emission signal energy, d) number of counts

The numerical simulations for the evaluation of structural damage were conducted using the Tsai-Wu failure criterion, which for the plane stress formulation in the composite layer can be written as [20]:

$$
\begin{aligned}
& F_{11} \sigma_{1}^{2}+2 F_{12} \sigma_{1} \sigma_{2}+F_{22} \sigma_{2}^{2}+ \\
& +F_{66} \tau_{12}^{2}+F_{1} \sigma_{1}+F_{2} \sigma_{2}=1
\end{aligned}
$$

The components of strength tensor, except for the $F_{12}$ can be determined in simple strength tests. 
The values of these components can be summarized as follows:

$$
\begin{gathered}
F_{1}=\frac{1}{X_{t}}-\frac{1}{X_{c}} \quad F_{2}=\frac{1}{Y_{t}}-\frac{1}{Y_{c}} \\
F_{11}=\frac{1}{X_{t} X_{c}} \quad F_{22}=\frac{1}{Y_{t} Y_{c}} \quad F_{66}=\frac{1}{S^{2}}
\end{gathered}
$$

where: $X_{t}, X_{c}, Y_{t}, Y_{c}$ are the empirically determined strength limits for the composite in tension and compression respectively in the fiber direction and in perpendicular direction. The S parameter defines a shear limit in the layer plane - see Table 1.

Tsai-Wu criterion takes into account the interactions between the components of the stress tensor $\sigma_{1}$ and $\sigma_{2}$ which is directly related to the coefficient $F_{12}$. To determine this coefficient performing of complex biaxial test is required. Mentioned test is very difficult to perform, because small differences in the values received can cause major changes in the shape of a limit curve, from the very elongated ellipse transition until the two hyperbolas. The value of this coefficient significantly affect the stability of the entire criterion and the closure of the limit curve in biaxial stress state. Example of the experimental designation of $F_{12}$ values for some composite materials present in their work Benzeggagh et al. [21] and Golaski [22]. In practice, wherever there is a lack of reliable experimental data to determine this ratio experimentally, as proposed by Tsai-Wu [20, 23, 24] coefficient can be determined as follows:

$$
F_{12}=\sqrt{\frac{1}{X_{t} X_{c} Y_{t} Y_{c}}}
$$

The value of failure initiation load for the first layer was set to be the value of load $P_{f(i n i)-F E M}$, equal to attaining failure parameter $l$ in the first layer of the composite material; in the discussed case, it was the internal layer of the channel section (Fig. 7). The components of the stress state in the layer were determined at the nodes where the parameter achieved critical value. Components of the state of stress in the layer are associated with the main orthotropy directions of the composite material, namely: $\sigma_{1}-$ stress in the fibers direction, $\sigma_{2}-$ stress in the perpendicular direction $\tau_{12}$ - shear stress in the plane of the layers, which are summarized in Table 2.

The obtained values clearly indicate the exceeding the limit stress $\sigma_{2}>Y_{t}$, which may suggest
Table 2. The stress state components corresponding to the load $P_{\text {f(ini)-FEM }}$

\begin{tabular}{|c|c|c|}
\hline \multicolumn{3}{|c|}{ The stress state components [MPa] } \\
\hline$\sigma_{1}$ & $\sigma_{2}$ & $\mathrm{~T}_{12}$ \\
\hline 184.7 & 28.2 & 16.9 \\
\hline
\end{tabular}

that it is precisely that this component will have a decisive impact on the criterion of damage in the layer. Taking into account that a strength of the layer in direction perpendicular to the fibers determines the strength of the matrix can be assumed that the failure initiation in the first layer is resulted by matrix failure. Unfortunately, at this stage of loading we could not locate micro-damages of the material using non-destructive methods however, as the exhibit overcritical path equilibrium of the structure - Figure 6, arising defects not reduce substantially the stiffness of the structure.

Table 3. Comparison of failure load values

\begin{tabular}{|c|c|c|c|c|c|}
\hline \multicolumn{2}{|c|}{ Failure initiation load } & \multicolumn{3}{c|}{$\begin{array}{c}\text { Failure load } \\
\mathrm{P}_{\mathrm{f}}[\mathrm{N}]\end{array}$} \\
\hline \multirow{3}{*}{ FEM } & \multicolumn{2}{|c|}{$\begin{array}{c}\text { Experimental } \\
\mathrm{P}_{\mathrm{f} \text { (ini)-FEM }}[\mathrm{N}]\end{array}$} & $\mathrm{P}_{\mathrm{f} \text { (ini)-EXP }}$ & \multirow{3}{*}{ FEM } & \multicolumn{2}{|c|}{$\begin{array}{c}\text { Experimental } \\
\mathrm{P}_{\mathrm{f}-E X P}\end{array}$} \\
\cline { 2 - 3 } \cline { 5 - 6 } & $\begin{array}{c}\text { Sample } \\
1\end{array}$ & $\begin{array}{c}\text { Sample } \\
\mathrm{P}_{\mathrm{f} \text {-FEM }}\end{array}$ & & $\begin{array}{c}\text { Sample } \\
1\end{array}$ & $\begin{array}{c}\text { Sample } \\
2\end{array}$ \\
\hline 4250 & 4650 & 4376 & 6750 & 7405 & 7742 \\
\hline
\end{tabular}

\begin{tabular}{|l|}
\hline TSAIW \\
Envelope (max abs) \\
(Avg: $100 \%$ ) \\
1.09 \\
1.00 \\
0.91 \\
0.82 \\
0.73 \\
0.64 \\
0.55 \\
0.46 \\
0.36 \\
0.27 \\
0.18 \\
0.09 \\
0.00 \\
Max: 1.09 \\
Elem: CEOWNIK-1.9368 \\
Node: 1329 \\
\hline
\end{tabular}
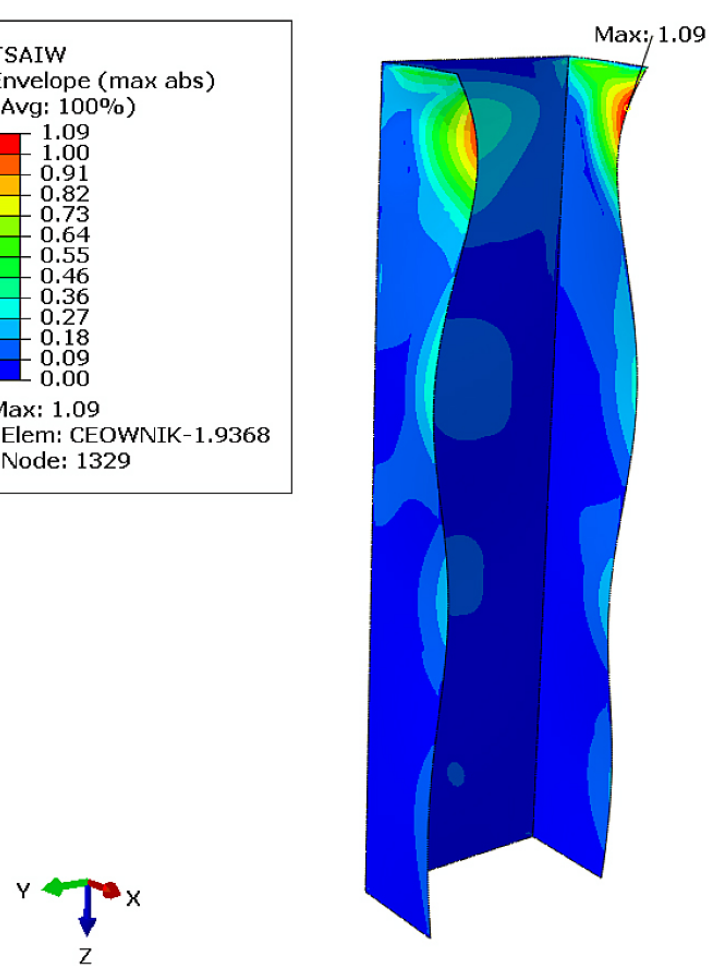

Fig. 7. Numerical analysis results - failure criterion is met in the first layer of the composite 
The simulations were being run until the failure criterion was met for all layers, attaining a load value equal to the failure load $P_{f-F E M^{*}}$ The load values obtained are compared in Table 3 .

The results demonstrate that there is a high quantitative agreement between the values of failure initiation load for the first layer and those of limit load, as the maximum differences do not exceed $13 \%$, which can be considered a high agreement of results with regard to stability problems. This confirms the suitability of the designed numerical models that simulate real conditions of the experiment.

The first stage of the tests to estimate the rage of damage caused in the composite columns by limit load loss of the structure involved locating visible areas of damage via careful inspection of the damaged sample combined with photographic documentation. The application of the NDT methods to scan the walls of the damaged columns enabled to estimate visible damaged areas and to locate potential internal failures in other areas of the microstructure $[25,26]$. To this aim, the A-scan, B-scan and C-scan methods were used. The employed scanning methods enabled to determine the depth of structural damage (A-scan), the depth of location as well as the width of damage in a given direction (B-scan and C-scan). The nondestructive test results demonstrate that the damage of the composite material is complex; the areas of the visible material damage reveal delamination and the cracking of matrix and reinforcing fibers. However, no microstructure discontinuity was observed, which may prove that the material failure was initiated in other areas of the profile. Figure 8 shows examples of the results obtained: damage area and its simulation by the NDT method.

a)

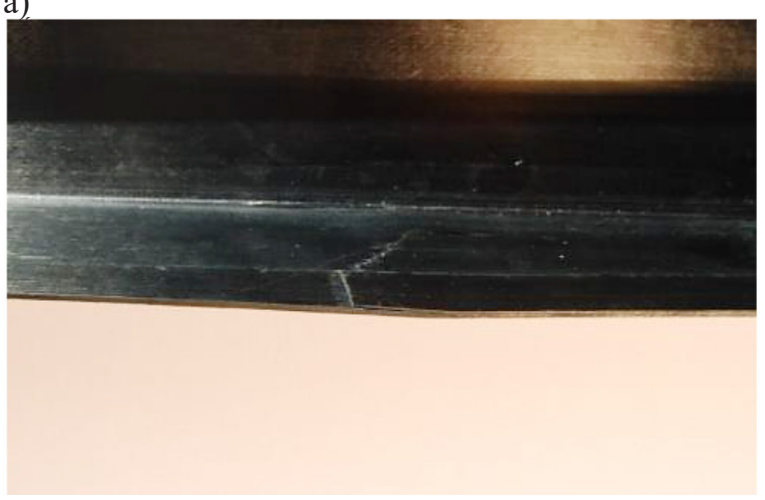

To estimate the nature of structural damage in the composite material, X-ray microtomography was used in the second stage of the experiments. In this stage, a $30 \times 50 \mathrm{~mm}$ sample with a visibly damaged area was cut out from the damaged column. The tests allowed to examine the damage area inside the composite material structure. In effect, they confirmed the nondestructive character of material damage, i.e. delamination as well as the cracking of matrix and reinforcing fibers (transverse cracking of the composite layers), as can be seen in Figure 9.

The examination of the composite microstructure shows the range of delamination, revealing, at the same time, the nature of buckling and damage of the composite fibers, along with cracks in the matrix and particular layers of the composite (Fig. 10).

The examination of the damaged composite columns performed with the use of the discussed laboratory methods confirm that the damage of the composite material structure is complex. The identified forms of material damage: delamination and cracking of reinforcing fibers and matrix, correspond to the cases of composite material damage described in the literature of the subject.

\section{CONCLUSION}

The study presented the research on postcritical and limit states of thin-walled channel section columns made of composite materials subjected to compression. The obtained results allow to describe the problem of non-linear stability and structural damage with the use of interdisciplinary research methods. Experimental tests performed on real structures are

b)

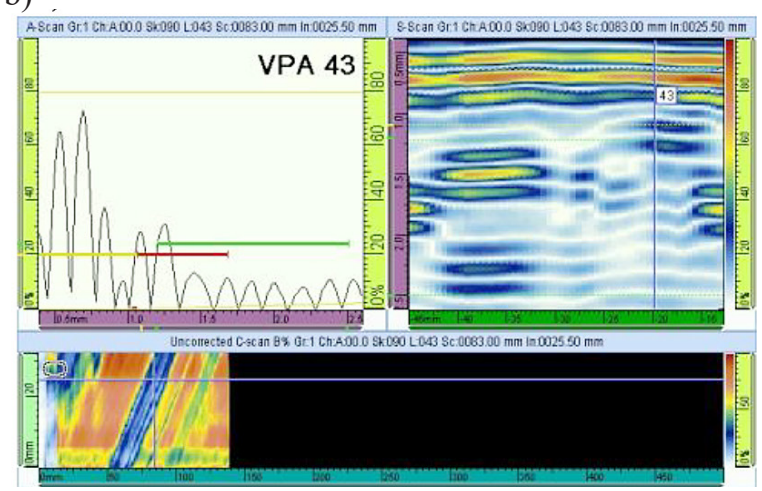

Fig. 8. Location of damage area in the column: a) damage area, b) NDT scan 

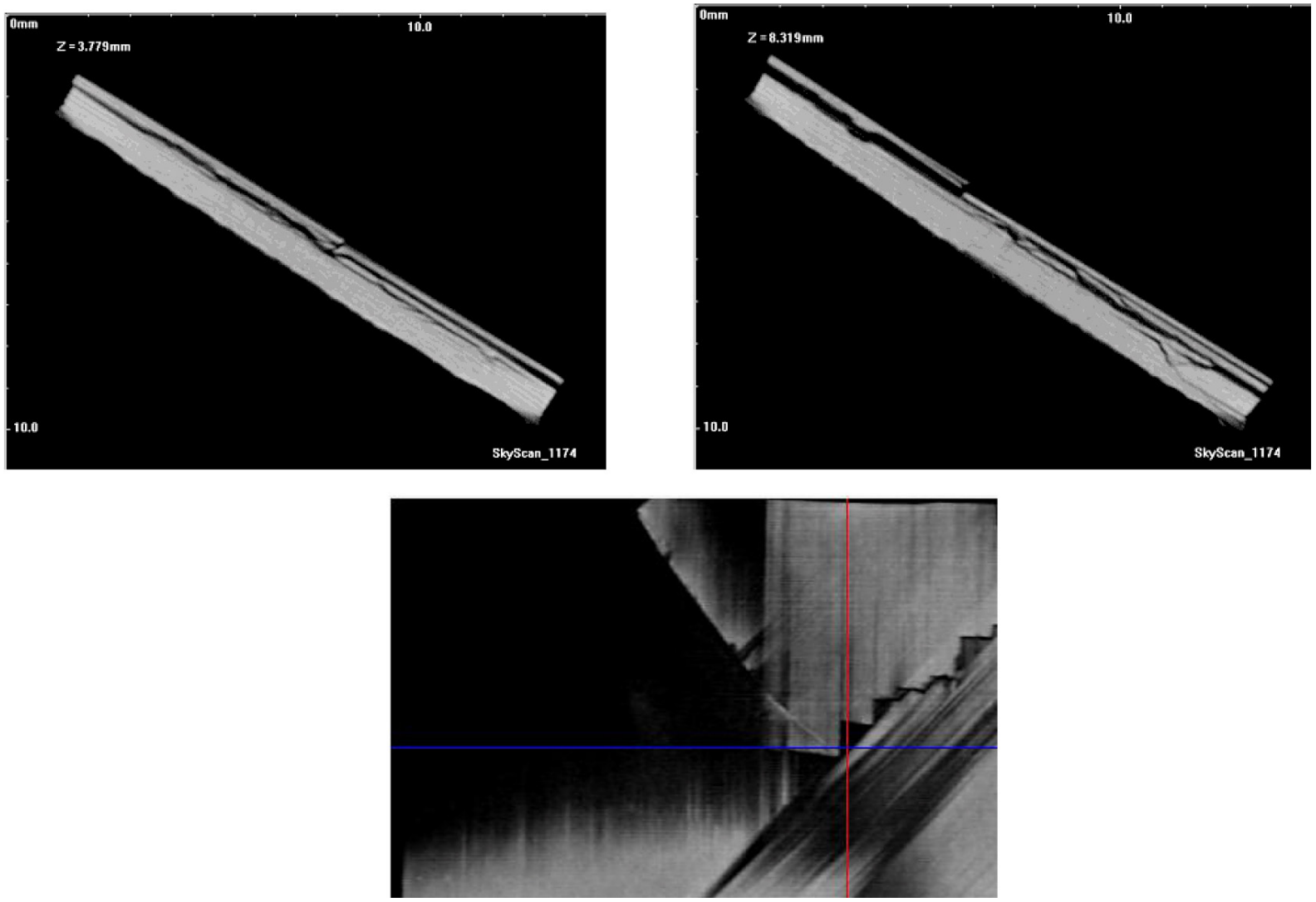

Fig. 9. X-ray microtomographic image of the damaged test sample

a)

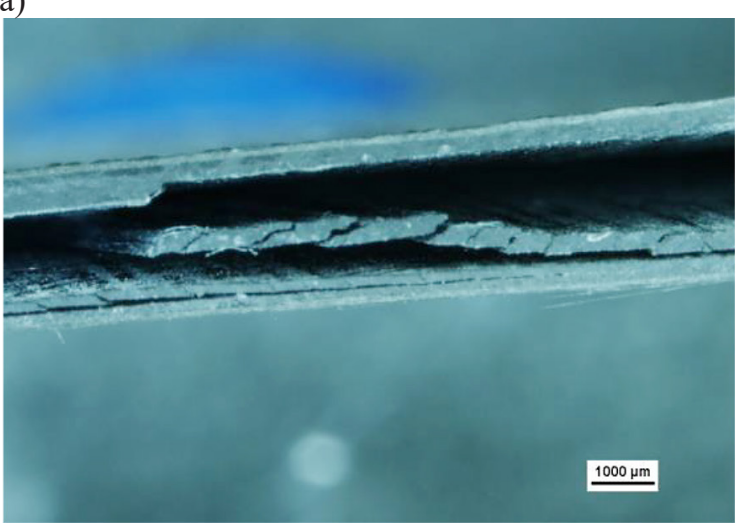

c屯)

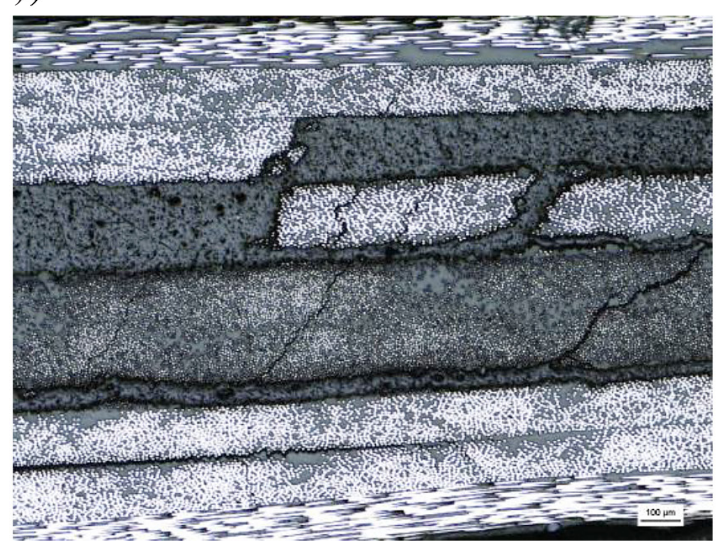

b)

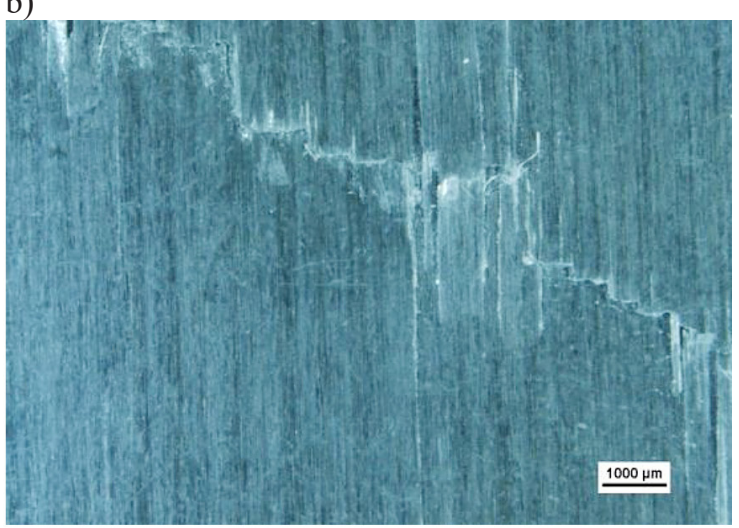

d) d)

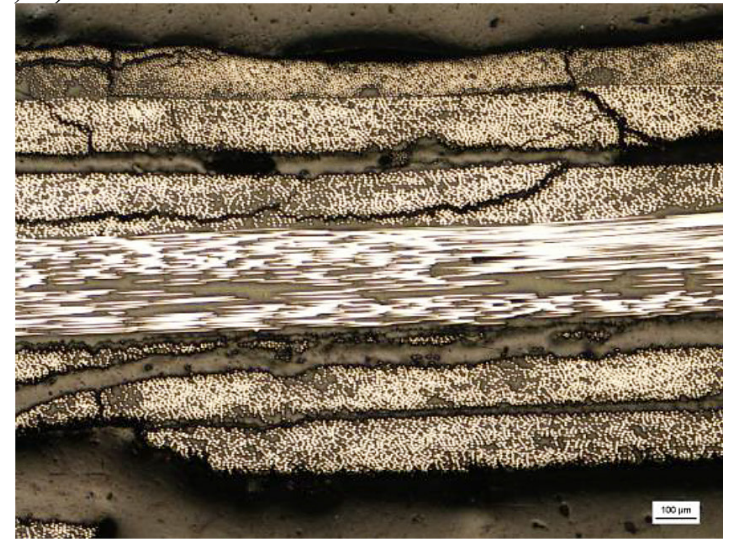

Fig. 10. Composite profiles damage: a) stereoscopic microscopy, b) damage area microstructure 
of particular significance here, because they allow that measurements be made by independent methods. In effect, the structure being examined can be described for entire load range, including a moment of failure. The conducted tests proved the suitability of applying the Acoustic Emission Method to analyze the experimental results. The results obtained thereby helped interpret the phenomena that occurred in loading and allowed to identify failure moment of the first layer of the composite material.

The experimental results allowed the development of adequate FEM numerical models that simulate real conditions of the experiment. This is proved by the obtained high agreement between the first layer's failure initiation load and limit load obtained in the experiments. Such non-linear numerical analysis allows to identify the state of stress in individual layers of the composite, revealing structure areas potentially prone to failure.

Macro- and microscopic methods for structural analysis of composite materials played a significant role in the conducted experiments. The discussed NDT, optical microscopy and $\mathrm{X}$-ray microtomography methods allow to identify the nature of damage of composite materials, where a type and range of failures can be estimated. The tests revealed that the nature of structural damage is complex, where delaminating and the cracking of reinforcing fibers and matrix in the composite material occur at the same time. This notwithstanding, for a more detailed examination of the nature of the damage process further research is required, where individual components of stress state will be investigated and their effect on the damage mechanism of composite materials will be estimated.

\section{Acknowledgments}

The project/research was financed in the framework of the project Lublin University of Technology-Regional Excellence Initiative, funded by the Polish Ministry of Science and Higher Education (contract no. 030/RID/2018/19).

\section{REFERENCES}

1. Jakubczak P., Bienias J., Majerski K., et al., The impact behavior of aluminum hybrid laminates, Aircraft Engineering and Aerospace Technology, Special Issue. 2014; SI(86): 287-294.
2. Bienias J., Surowska B., Jakubczak P. The Comparison of Low-Velocity Impact Resistance of Aluminum/Carbon and Glass Fiber Metal Laminates. Polymer Composites. 2016; 37: 1056-1063.

3. Dadej K., Bienias J., Surowska B. Residual fatigue life of carbon fibre aluminium laminates. International Journal of Fatigue. 2017; 1(100): 94-104.

4. Campbell F.C. Manufacturing Processes for Advanced Composites. Elsevier; 2004.

5. Campbell F.C. Manufacturing Technology for Aerospace Structural Materials. Elsevier; 2006.

6. Mason K.Autoclave Quality Outside the Autoclave? High Performance Composites; 2006:March.

7. Prepreg technology, Hexcel Publication; 2005. www.hexcel.com

8. Bohse J. Damage analysis of polymer matrix composites by acoustic emission testing, Proceedings of European Working Group on Acoustic Emission, Berlin. 2004; 339-348.

9. http://www.vallen.de.

10. Ye J., Zhang B., Qi H. Cost estimates to guide manufacturing of composite waved beam. Materials and Design. 2009; 30: 452-458.

11. Habermehl J., Lamarre A. Ultrasonic phased array tools for composite inspection during maintenance and manufacturing. In: 17 th world conference on nondestructive testing, Shanghai, China 2008, 832-839.

12. Bienias J., Jakubczak P., Majerski K., et al., Methods of ultrasonic testing, as an effective way of estimating durability and diagnosing operational capability of composite laminates used in aerospace industry. Eksploatacja i niezawodność - Maintenance and Reliability. 2013; 15: 284-289.

13. Dębski H., Teter A., Kubiak T., Samborski S. Local buckling, post-buckling and collapse of thin-walled channel section composite columns subjected to quasi-static compression. Composite Structures. 2016; 136: 593-601.

14. Dębski H., Jonak J. Failure analysis of thin-walled composite channel section columns. Composite Structures. 2015; 132: 567-574.

15. Kopecki T., Mazurek P. Problems of numerical bifurcation reproducing in post-critical deformation states of aircraft structures, Journal of Theoretical and Applied Mechanics. 2013; 51: 969-977.

16. Kopecki T., Mazurek P. Numerical representation of post-critical deformations in the processes of determining stress distributions in closed multisegment thin-walled aircraft load-bearing structures, Eksploatacja i Niezawodnosc-Maintenance and Reliability. 2014; 16: 164-169.

17. Falkowicz K., Ferdynus M., Dębski H. Numerical analysis of compressed plates with cut-out operating in the geometrically nonlinear range, Eksp- 
loatacja i Niezawodnosc-Maintenance and Reliability. 2015; 17: 222-227.

18. Abaqus HTML Documentation.

19. Reddy J.N. Mechanics of laminate composite plates, theory and analysis, CRC Press LLC, Baca Raton; 2004.

20. Tsai S.W., Wu E.M. A general theory of strength for anisotropic materials, J. Compos. Mater. 1971; 24: 58-80.

21. Benzeggagh M.L., Khellil K., Chotard T. Experimental determination of Tsai Failure Tensorial Terms $F_{i j}$ for unidirectional composite material, Composites Science and Technology. 1995; 55: 145-156.

22. Golaski L. Failure criteria for laminates under combined loading conditions, in: D. Francois, L. Golaski (Eds.), Joint Seminary on Failure of Advanced
Materials, Kielce University of Technology, ParisKielce; 1996; 37-61.

23. Altenbach H., Altenbach J. W. Kissing, Structural analysis of laminate and sandwich beams and plates. An introduction into the mechanics of composite, Lubelskie Towarzystwo Naukowe, Lublin; 2001.

24. Tsai S.W. Composites Design, Fourth Edition, Think Composites, Dayton, Paris, and Tokyo; 1988.

25. Capitani V., Capriolo M., Sendi D. Characterization of Casting Defects in Composite Carbon Fiber Material Detected by Ultrasonic Inspection, Ultrasund. 2011; 66: 14-20.

26. Schnars U., Henrich R. Applications of NDT Methods on Composite Structures in Aerospace Industry, Proceedings of CDCM 2006 - Conference on Damage in Composite Materials, Stuttgart, Germany 2006. 